\title{
Association of Weight Misperception with Unhealthy Diet-related Behaviors among University of the Philippines Manila Undergraduate Students
}

\author{
Migel Antonio P. Catalig,,$^{1,2}$ Novee Lor C. Leyso, ${ }^{3}$ Venju P. Estrellado, ${ }^{3}$ Paul Adrian V. Pinlac ${ }^{3}$ and Kim L. Cochon ${ }^{3}$ \\ ${ }^{1}$ Department of Physical Sciences and Mathematics, College of Arts and Sciences, University of the Philippines Manila \\ ${ }^{2}$ De La Salle-College of St. Benilde Manila \\ ${ }^{3}$ College of Public Health, University of the Philippines Manila
}

\begin{abstract}
Objectives. The study aims to determine whether there is an association of perceived weight status with unhealthy diet practices.

Method. An analytic cross-sectional study was conducted among 625 adult undergraduate students from U.P. Manila. The survey included questions regarding sociodemographic status, habits related to diet and weight management, and perceived body mass index (BMI). Actual BMI were obtained and calculated from actual anthropomorphic measurements.

Results. In the population surveyed, it was seen that $53.28 \%$ of the students accurately perceived their BMI status, $26.08 \%$ overestimated their BMI status, while $17.28 \%$ underestimated their BMI status. It was also seen that over-estimating of BMI status is more associated with unhealthy diet practices. Those who over estimated their BMI were 1.95 times more likely to skip meals $(p=0.001)$ and 1.56 times more likely to engage in cutting of food ( $p=0.034)$. Physical activity was also seen to be associated with these practices.
\end{abstract}

Conclusion. Over-estimation of BMI may be linked to unrealistic goals in weight loss resulting in unhealthier diet-related habits.

Key Words: dietary habits, body mass index, weight perception, unhealthy eating practices, physical activity, weight management

\section{INTRODUCTION}

Corresponding author: Migel Antonio P. Catalig, MSc Department of Physical Sciences and Mathematics College of Arts and Sciences

University of the Philippines Manila

Padre Faura St., Ermita, Manila 1000, Philippines

Email:mpcatalig@up.edu.ph
Several studies have well documented the growing adoption of unhealthy weight-loss practices (e.g., fasting, eating very little and skipping meals) and extreme (e.g., consumption of diet pills, use of laxatives and diuretics) among adolescents and young adults. Studies have also shown that these behaviors occur naturally and without any professional guidance or advice. Thus, this may result in higher risk of unhealthy eating patterns, consequently, gaining more weight over time. Risks of developing obesityrelated disease are also more likely. ${ }^{1}$

Many factors, both individual and external, contribute to developing these behaviors. One external factor would be the growing worldwide awareness on weight management as well as promotion of healthy diets and increased physical activity to address the "obesity epidemic" and its subsequent 
diseases. ${ }^{1,2}$ At the same time, the multi-billion-dollar weightloss industry has driven the demand and supply of different weight loss products around the world. Retail sales of weight-loss supplements amounted to more than $\$ 1.3$ billion in the United States in 2001. ${ }^{3}$ Prevalence studies on use of non-prescription lifestyle drugs was also shown to be more common. ${ }^{4}$ Euromonitor International reported that sales of meal replacement slimming and weight-loss supplements is growing. ${ }^{5}$ Another factor that also encourages individuals to undertake unhealthy and extreme behaviors to lose weight is the portrayal of media relating to standards of beauty and thinness. Media has overemphasized the idea of being thin as healthy and beautiful in which attaining the ideal body weight leads to social acceptance and peer approval. ${ }^{6}$

Nevertheless, individual factors also facilitate practice of unhealthy and extreme weight-loss behaviors such as selfperceived and actual measures of body weight. ${ }^{1}$ Growing evidence on discordance between these two individual factors (i.e., self-perceived versus actual body weight) influences the adoption of weight-loss behaviors differently among the general population especially among adolescents and young adults. ${ }^{1,7}$

\section{Weight Misperception and Weight Management Practices}

Body dissatisfaction is often associated with weight misperception. It is described as disagreement between an individual's actual weight status and the perception of one's weight. It could also bring about potentially dangerous weight control behaviors like skipping meals and taking laxatives. ${ }^{7}$

Results of a study in Pakistan showed that weight and body mass index (BMI) underestimation was more common among males while overestimation was common among females. Odds of weight misperception were remarkably less on students of medical sciences, engineering, and business administration compared to other students. ${ }^{8}$

Several studies revealed that weight misperception was associated with health risk behaviors among young adults and adolescents. ${ }^{1,7-13}$ For instance, a study that utilized the 2011 YRBS cross-sectional data showed that weight misperception, both overestimation and underestimation, was associated with health risk behaviors related to safety and violence, mental health, substance use, dieting, and physical inactivity. Adjusting for age, sex, and race, results showed that those who inaccurately perceived their weight are more likely to engage in health risk behaviors than those who accurately perceived their weight. Across sex, boys and girls have similar pattern in general. In relation to the use of diet pills for weight loss, the same study revealed that those who moderately overestimated, highly underestimated, and highly overestimated their weight had 2.3,3.3, and 4.7 times higher odds of using diet pills as compared to those who correctly estimated their weight, respectively. ${ }^{9}$

In a different study using 2009 Youth Risk Behavior Surveillance data, inaccurate weight perception lead to significantly higher odds of undertaking Extreme Weightmanagement Practices (EWPs) such as fasting for 24 hours, taking non-prescription diet pills, and purging to lose weight, compared to accurate perceivers among students of both sexes who were of healthy weight. In addition, underweight females who over assessed their weight had 12.6 times higher odds of engaging in EWPs (95\% CI: 3.4-46.6). Results also revealed that healthy-weight students who overestimated their weight had higher odds of engaging in EWPs. It was also seen that sex and actual BMI category were found to be effect measure modifiers in this study. ${ }^{10}$

In a study that focused only on female Australian school girls aged 14-16, variables such as the desire to have "ideal" body shape, male friends suggesting the girl as underweight, currently trying to lose weight, family members suggesting the girl was overweight, and other people suggesting the girl as overweight were found to be significantly correlated with extreme dieting behaviors such as crash dieting and use of slimming tablets, diuretics, laxatives, and cigarettes. Amount of exercise was also considered as correlate of extreme dieting behaviors but was not found to be significant. ${ }^{11}$ Membership to a sexual minority group was also associated with weight misperception. Heterosexual males with prior same-sex partners and bisexual males were more likely to self-perceive as overweight and are also more likely to engage in unhealthy weight control behaviors. ${ }^{12}$ Furthermore, Unhealthy Weight Control Behaviors (UWCB) was also shown to be significantly associated with substance use, being bullied, suicidal behavior, tobacco use, and physical and sexual violence, based on data from Youth Risk Behavior Surveillance in the United States. ${ }^{13}$

Locally, the Philippine Association for the Study of Overweight and Obesity (PASOO) is a national organization with the mission to pioneer in the prevention and control of obesity and its complications through education, research, and advocacy. They have taken an exhaustive review of all existing researches on obesity in Filipinos between 1981 and 2011. They have reported that in 2008, prevalence of overweight and obese adults has reached 21.4 percent and 5.2 percent, respectively. ${ }^{14}$ However, very few studies in the Philippines attempt to link weight status to perceived weight status, much less so, relate it to actual behavior. This study aimed to determine whether weight misperception was associated with unhealthy diet related behavior among undergraduate students at the University of the Philippines Manila.

\section{STUDY VARIABLES AND OPERATIONAL DEFINITIONS}

\section{Exposure Variable}

Weight misperception is the difference between the individual's perceived weight status and actual weight status as measured by age-specific Body Mass Index (BMI) status. Weight misperception can be classified into three categories, namely over-estimators, accurate perceivers and underestimators. Over-estimators are individuals who have higher 
perceived BMI status in contrast to actual BMI status, while under-estimators have lower perceived BMI status in contrast to actual BMI status. Accurate perceivers have the same perceived and actual BMI status.

Body Mass Index as defined by World Health Organization (WHO) is a simple weight for height index used to classify weight status of individuals. To compute for BMI, individual's weight in kilograms is divided by the square of his $/$ her height measured in meters $\left(\mathrm{kg} / \mathrm{m}^{2}\right)$. Values of BMI can be classified into 4 categories such as underweight $(\mathrm{BMI}<18.5)$, normal $(18.5 \leq \mathrm{BMI}<25)$, overweight $(25 \leq \mathrm{BMI}<30)$, and obese (BMI $\geq 30)$. In this study, classification of BMI status was age-specific. For adults 20 years old and above, the following BMI cutoff points and classification from WHO was adopted. For individuals aged 18 and 19, the BMI calculation was the same. However, the BMI classification was according to the BMI percentile which is sex-specific and age-specific. An excel template was used to identify which BMI percentile each respondent belonged to. The template is available at the Center for Disease Control and Prevention. ${ }^{15}$

Perceived weight status is an individual's idea or perception of his/her weight as described by the question: "Do you consider yourself to be underweight, about the right weight, overweight, or obese?"

Actual weight status is an individual's anthropometric (height and weight) data measured right after the questionnaires were administered. Height was measured in centimeters and converted to meters, and weight was measured in kilograms.

\section{Outcome Variables}

Diet-related behaviors featured in the study are: skipping meals - did not eat at least one full meal such as breakfast, lunch or dinner in a day and cutting out food - did not eat at least one important food group. The first behavior can be answered by checking whether the participant practice skipping meals through one's response on the questionnaire. Cutting out of food can be determined by selecting at least one yes among a list of food in the questionnaire.

\section{Possible Confounders}

Age, sex, course, socialized tuition system (STS) bracket, and physical activity were collected using a survey questionnaire. The course would refer to the specific undergraduate course in University of the Philippines Manila. STS is an official tuition bracketing system of the University of the Philippines which classifies the financial capacity of the students to pay their tuition based on the student's household income. ${ }^{16}$ Possible answers are A, B, $\mathrm{C}, \mathrm{D}, \mathrm{E} 1$, and E2, in order of decreasing financial capacity. Lastly, the amount of physical activity is the number of days per week the participants engages in at least 60 minutes of moderate or vigorous activity in addition to normal daily routine. Possible answers range from 0 to 7 days.

\section{METHODS}

An analytical cross-sectional study design was used. The exposure variable under study consisted of participant's perception of their BMI status and actual BMI status based on measured height and weight at the time of data collection. Information on the outcome variables was obtained through the responses of the participants using recall without the need to follow up.

\section{Study Population and Participation Recruitment}

The study involved all undergraduate students of the University of the Philippines Manila, at least 18 years of age and taking at least third year major subjects, and officially enrolled for the $2^{\text {nd }}$ semester of the academic year 2016-2017. Data collection occurred within the months of February and April 2017. Students were grouped according to their courses, and courses with higher number of students had higher number of recruited participants. Students were recruited from the different courses through their major classes.

\section{Data Collection Procedure}

Prior to the data collection proper, a dry-run of the whole data collection procedure was done in a small class of $4^{\text {th }}$ year undergraduate students of the College of Arts and Sciences held in first semester of Academic Year 2016-2017. The dry-run included testing two separate set-ups (for males and females) for the measuring instruments to be used for height and weight, pre-testing the questionnaire as well as the informed consent.

In preparation for the data collection, formal letters were sent to the deans of the different colleges informing them of the study that will be conducted among their undergraduate students. Another letter was sent out to all professors of the selected subjects asking for their permission to conduct the data collection for 15 minutes, preferably at the end of the class. Aside from a formal letter, professors and instructors from selected subjects were also informed through email. The email comprised of a request together with attachments of Research Ethics Board clearance and the full protocol of the study. Once the professors provided permission, the date was then set for the conduct of the data collection.

Before the start of the survey proper, the students were informed regarding the background of the study as well as its objectives. The informed consent was then discussed by the researchers in detail informing the participants of their rights should they choose to participate or not. A short open forum followed to accommodate any question or clarification from the students. After all questions or clarifications were addressed, the data collection proper started by providing all respondents with the informed consent form and a self-administered questionnaire. After the respondents had completed the questionnaire, the respondents' actual height and weight were determined separately for males 
and females in which a male researcher measured the height and weight of male respondents. The same procedure was also done for female respondents in which their height and weight were measured by a female researcher. Figure 1 shows a set-up that measures both height and weight for female participants. A bathroom weighing scale (maximum capacity: $150 \mathrm{~kg}$ ) was used to obtain the weight of the participant. For height, a tape measure system placed on the wall was used.

The questionnaire developed for this study was adopted mainly from the Youth Risk Behavior Survey ${ }^{17}$ (YRBS) conducted by Center for Disease Control and Prevention in the US. The data collection instrument is composed of 10 questions, regarding sociodemographic profile, diet related habits in the past 3 months, weight perception, and amount of physical activity.

\section{Data Processing and Analysis}

Data collection involved participants answering a 1-page paper questionnaire and measuring their actual height and weight. Responses of the participants on the questionnaire as well as the actual data on height and weight were encoded in Microsoft Excel and analyzed using STATA 12.

\section{RESULTS}

\section{Descriptive Statistics}

Table 1 shows the socio-demographic profile of the sampled undergraduate students. All participants were aged above 18 years, with an average age of 19.6 and maximum age of 26. More than half of the participants were aged between 18 and 19. Two-thirds of the respondents were females. Classifying the participants by degree program showed that around 80 percent of them were enrolled under a Bachelor of Science degree program. More than one-third (35.4\%) of the participants belonged to the highest STS bracket which is bracket $\mathrm{A}$. About 30 percent belonged to the second highest bracket which is bracket $\mathrm{B}$, while nearly 24 percent were classified to be in bracket C. Only 5.6 percent of the respondents were in bracket $\mathrm{D}$ and 3 percent in bracket E. About 2 percent of the respondents were dependents of UP Manila and PGH employees. In terms of physical activity, the average number of days allotted by the respondents on physical exercise at least one hour a day was 1.7 days. However, nearly one-third reported to have not allotted any single day for any physical exercise of at least one hour a day.

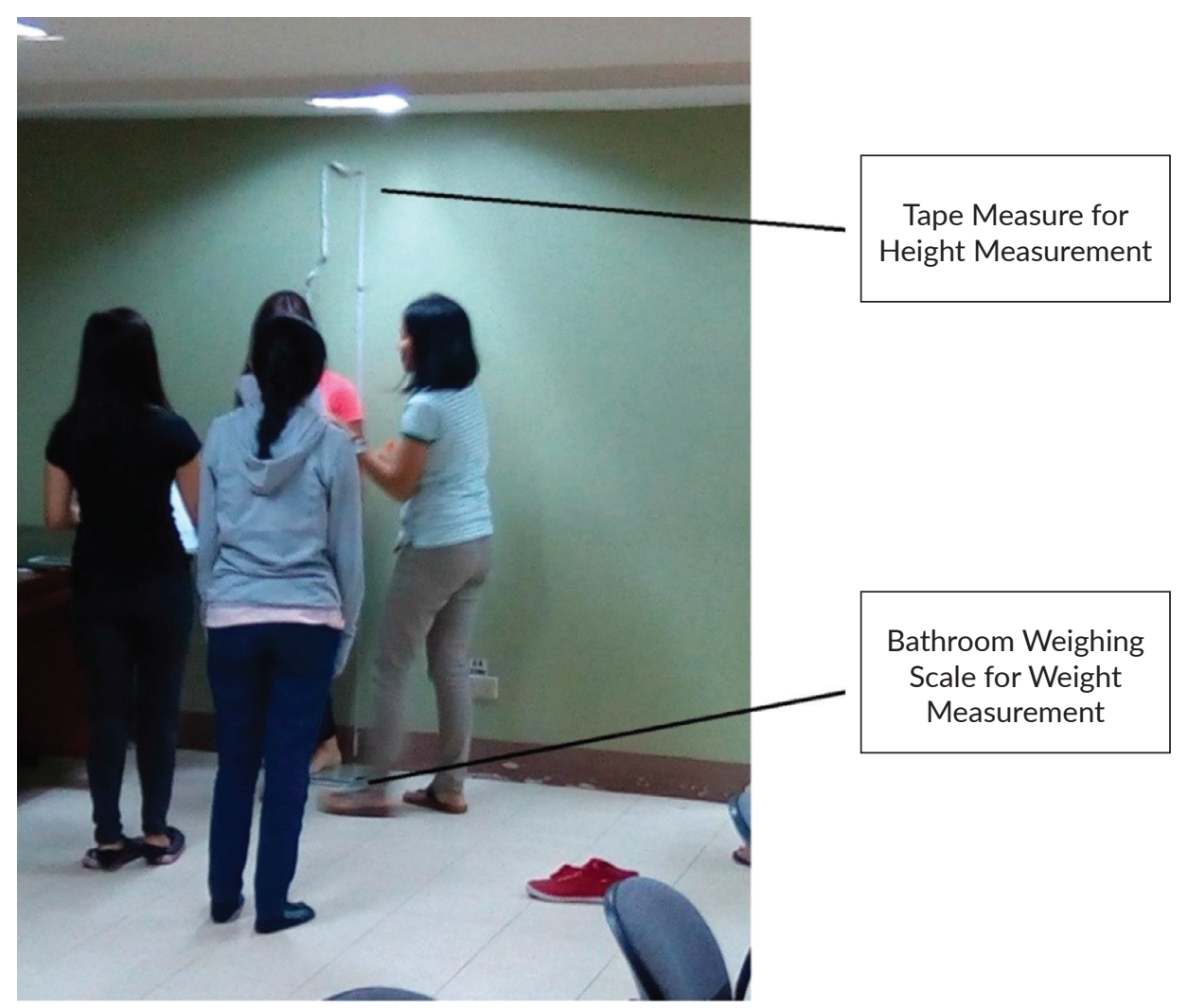

Figure 1. Illustration of Actual Height and Weight Measurement for Female Participants. 
Table 1. Socio-demographic and Physical Activity Profile of Selected Undergraduate Students of UPM $2^{\text {nd }}$ Semester AY 2016-2017

\begin{tabular}{|c|c|c|c|c|c|c|c|}
\hline Variable & No & $\%$ & $\mathbf{N}$ & Mean & Std Dev & Min & Max \\
\hline Age & & & 624 & 19.6 & 1.0 & 18 & 26 \\
\hline 18-19 & 335 & 53.7 & & & & & \\
\hline 20 and above & 289 & 46.3 & & & & & \\
\hline \multicolumn{8}{|l|}{ Sex } \\
\hline Male & 206 & 33.0 & & & & & \\
\hline Female & 419 & 67.0 & & & & & \\
\hline \multicolumn{8}{|l|}{ Course } \\
\hline BA Behavioral Sciences & 17 & 2.7 & & & & & \\
\hline BA Development Studies & 24 & 3.8 & & & & & \\
\hline BA Organization Communication & 29 & 4.6 & & & & & \\
\hline BA Philippines Arts & 18 & 2.9 & & & & & \\
\hline BA Political Science & 15 & 2.4 & & & & & \\
\hline BA Social Sciences & 29 & 4.6 & & & & & \\
\hline BS Applied Physics & 18 & 2.9 & & & & & \\
\hline BS Biochemistry & 30 & 4.8 & & & & & \\
\hline BS Biology & 69 & 11.0 & & & & & \\
\hline BS Computer Science & 14 & 2.2 & & & & & \\
\hline BS Industrial Pharmacy & 65 & 10.4 & & & & & \\
\hline BS Nursing & 47 & 7.5 & & & & & \\
\hline BS Occupational Therapy & 26 & 4.2 & & & & & \\
\hline BS Pharmacy & 54 & 8.6 & & & & & \\
\hline BS Physical Therapy & 24 & 3.8 & & & & & \\
\hline BS Public Health & 76 & 12.2 & & & & & \\
\hline BS Speech Pathology & 18 & 2.9 & & & & & \\
\hline Doctor of Dental Medicine & 52 & 8.3 & & & & & \\
\hline \multicolumn{8}{|l|}{ College } \\
\hline CAS & 263 & 42.1 & & & & & \\
\hline CAMP & 68 & 10.9 & & & & & \\
\hline Dentistry & 52 & 8.3 & & & & & \\
\hline Nursing & 47 & 7.5 & & & & & \\
\hline Pharmacy & 119 & 19.0 & & & & & \\
\hline Public Health & 76 & 12.2 & & & & & \\
\hline \multicolumn{8}{|l|}{ Degree } \\
\hline BS & 493 & 78.9 & & & & & \\
\hline BA & 132 & 21.1 & & & & & \\
\hline \multicolumn{8}{|l|}{ STS bracket } \\
\hline A & 221 & 35.4 & & & & & \\
\hline B & 185 & 29.6 & & & & & \\
\hline C & 149 & 23.8 & & & & & \\
\hline $\mathrm{D}$ & 35 & 5.6 & & & & & \\
\hline $\mathrm{E}$ & 16 & 2.6 & & & & & \\
\hline UP Dependent & 13 & 2.1 & & & & & \\
\hline Missing & 6 & 1.0 & & & & & \\
\hline \multicolumn{8}{|l|}{ STS Bracket Regrouped } \\
\hline A & 221 & 35.4 & & & & & \\
\hline B & 185 & 29.6 & & & & & \\
\hline Others & 213 & 34.1 & & & & & \\
\hline Missing & 6 & 1.0 & & & & & \\
\hline Days allotted for physical activity & & & 620 & 1.7 & 1.7 & 0 & 7 \\
\hline 0 & 205 & 32.8 & & & & & \\
\hline $1-2$ & 236 & 37.76 & & & & & \\
\hline More than 2 & 179 & 28.64 & & & & & \\
\hline Missing & 5 & 0.8 & & & & & \\
\hline $\mathrm{N}$ & 625 & 100.0 & & & & & \\
\hline
\end{tabular}


Table 2. Cross-tabulation of perceived BMI status and actual BMI Status Selected Undergraduate Students of UPM $2^{\text {nd }}$ Semester AY 2016-2017

\begin{tabular}{|c|c|c|c|c|c|c|}
\hline \multirow{2}{*}{ Perceived BMI Status } & \multicolumn{5}{|c|}{ Actual BMI Status } & \multirow{2}{*}{ Total } \\
\hline & Underweight & Normal & Overweight & Obese & Missing & \\
\hline Underweight & 29 & 33 & 10 & 4 & 1 & 77 \\
\hline Normal & 28 & 246 & 31 & 13 & 11 & 329 \\
\hline Overweight & 11 & 103 & 42 & 17 & 1 & 174 \\
\hline Obese & 3 & 11 & 7 & 16 & 1 & 38 \\
\hline Missing & 1 & 0 & 0 & 0 & 6 & 7 \\
\hline Total & 72 & 393 & 90 & 50 & 20 & 625 \\
\hline
\end{tabular}

Table 3. Distribution of respondents by Weight Perception, Undergraduate Students of UPM $2^{\text {nd }}$ Semester AY 2016-2017

\begin{tabular}{lcc} 
Weight Perception & Number & Percentage \\
Underestimated & 108 & 17.3 \\
Accurately estimated & 333 & 53.3 \\
Overestimated & 163 & 26.1 \\
Missing & 21 & 3.4 \\
\hline Total & 625 & 100 \\
\hline
\end{tabular}

\section{Weight Misperception}

The main exposure variable measured in this study was weight misperception, which was determined by the selfreported BMI status and the actual BMI status based on height and weight measurements. Table 2 shows the crosstabulation between these two variables. Frequencies on the main diagonal of the matrix represent those participants whose self-reported BMI status is the same with their actual BMI. More than half of the participants (53.3\%) were able to correctly report their BMI status. On the other hand, the off-diagonal frequencies on the right are those participants who have under-estimated their BMI status, which is 17 percent of the participants. Lastly, off-diagonal entries on the left of the matrix are those participants who over-estimated their BMI status, which corresponds to $26.1 \%$ of the participants. Table 3 summarizes the number of under estimators, accurate perceivers, and over estimators.

Weight misperception was prevalent among aged 20 and above as compared to aged 18-19. In terms of sex, overestimation was prevalent among females, while underestimation was prevalent among males. Overestimation was highest among the STS bracket A, while underestimation was relatively higher among those in STS bracket B. In terms of differences among courses however, College of Pharmacy had the highest proportion of over-estimators, and College of Dentistry had the highest proportion of those who underestimate their BMI status. In terms of physical activity, most of those who do not exercise at all underestimated their weight, and those who exercise at least 1-2 days tended to overestimate their BMI status.

\section{Skipping at least one meal a day}

In terms of the outcome variable on skipping at least one meal a day, one-third of the participants were engaged in this unhealthy diet-related behavior 3 months prior to the survey.

Table 4 gives a breakdown of those who skipped meals and their weight misperception status. Based on the table below, majority of those who skipped their meals had the correct estimate of their BMI status. These are then followed by those who overestimated their weight. It can be seen from among the students who skipped meals that there was a higher proportion of them that overestimated their BMI status in comparison to students that did not skip meals. Furthermore, there was a lower proportion of students who underestimated their BMI status that skipped meals in comparison to those that did not skip meals.

Table 5 breaks down the relationship of skipping meals with the possible confounders. Those that engaged in physical activity were $1.55(\mathrm{p}=0.043)$ times more likely to skip meals. It might be argued that those who engage in physical activity are more conscious of their weight and hence are more likely to explore methods to monitor their weight and diet. If they are overweight and are beginning to increase their physical activity to decrease their weight,

Table 4. Respondents' Weight Misperception by practice of Skipping at Least 1 Meal, Undergraduate Students of UPM $2^{\text {nd }}$ Semester AY 2016-2017

\begin{tabular}{|c|c|c|c|c|c|c|c|c|}
\hline \multirow{3}{*}{ Weight Misperception } & \multicolumn{8}{|c|}{ Skipping Meals } \\
\hline & \multicolumn{2}{|c|}{ No } & \multicolumn{2}{|c|}{ Yes } & \multicolumn{2}{|c|}{ Missing } & \multicolumn{2}{|c|}{ Total } \\
\hline & No & $\%$ & No & $\%$ & No & $\%$ & No & $\%$ \\
\hline Accurately estimated & 235 & 56.76 & 98 & 47.11 & 0 & 0 & 333 & 53.3 \\
\hline Overestimated & 90 & 21.74 & 73 & 35.10 & 0 & 0 & 163 & 26.1 \\
\hline Underestimated & 80 & 19.32 & 28 & 13.46 & 0 & 0 & 108 & 17.3 \\
\hline Missing & 9 & 2.17 & 9 & 4.33 & 3 & 100 & 21 & 3.4 \\
\hline
\end{tabular}


Table 5. Odds ratio and $\mathrm{p}$-value of probable confounders for skipping at least a meal a day, Undergraduate Students of UPM $2^{\text {nd }}$ Semester AY 2016-2017

\begin{tabular}{lll}
\hline \multicolumn{1}{c}{ Variable } & OR & p-value \\
$\begin{array}{l}\text { Age group } \\
\text { 18-19 }\end{array}$ & Base & \\
20 and above & 1.21 & 0.255 \\
\hline Sex & & \\
$\quad$ Male & Base & \\
$\quad$ Female & 1.04 & 0.825 \\
\hline STS & & \\
A & Base & \\
B & 1.26 & 0.275 \\
C, D, E and others & 0.98 & 0.934 \\
\hline Degree & & \\
Bachelor of Science & Base & \\
Bachelor of Arts & 1.09 & 0.696 \\
\hline UPM colleges & & \\
Arts and Sciences & Base & \\
Allied Medical Professions & 0.47 & 0.028 \\
Dentistry & 1.73 & 0.074 \\
Nursing & 1.15 & 0.680 \\
Pharmacy & 1.06 & 0.792 \\
Public Health & 1.11 & 0.691 \\
\hline Physical Activity & & \\
None & Base & \\
1-2 days & 1.25 & 0.289 \\
more than 2 days & 1.55 & 0.043 \\
\hline
\end{tabular}

Table 6. Reduced model of the Association between Skipping Meals and Weight Misperception, Undergraduate Students of UPM $2^{\text {nd }}$ Semester AY 2016-2017

\begin{tabular}{cccccc} 
Variable & $\begin{array}{c}\text { Odds } \\
\text { ratio }\end{array}$ & $\begin{array}{c}\text { Std } \\
\text { Error }\end{array}$ & p-value & $\mathbf{9 5 \%} \mathbf{C l}$ \\
Weight Misperception & & & & & \\
Same estimate & Base & & & & \\
Over estimate & 1.95 & 0.39 & 0.001 & 1.32 & 2.87 \\
Under estimate & 0.84 & 0.21 & 0.484 & 0.51 & 1.37 \\
Constant & 0.42 & 0.05 & $<0.001$ & 0.33 & 0.53 \\
\hline
\end{tabular}

then they are more likely to also skip meals with the aim of losing weight. Among those with correct perception of their weight, they could probably skip meals during times when they over-indulged with food. Hence, those who were more aware of their weight status were more likely to react to sudden changes in their diet (i.e. over-indulgence) with intention to counter their "unhealthy" past actions.

It is also worth noting that differences in age, gender, and bracket system are not probable confounders. Based on this study, there is no sufficient evidence to support that females are more likely to skip meals than their male counterparts. There is also no sufficient evidence to support that older students are more likely to skip meals. Using the method of Hosmer and Lemeshow, ${ }^{18}$ it was observed that the confounders were not significant and did not significantly change the odds ratio of outcome of skipping meals with weight misperception as the exposure variable. (Table 6)

Based on Table 6, those who overestimate their status of body mass index are 1.95 times $(p=0.001)$ more likely to skip meals. This might be caused by the fact that overestimating their BMI status results in a higher goal of losing weight. This might lead the student to look for different ways to lose weight, in which skipping meals is one of the perceived simple ways to implement. There was no statistical difference between those who underestimated their BMI status with those who correctly estimated their actual BMI status. This is probably because gaining weight and maintaining weight are not usually associated with habits related to losing weight, such as taking diet pills, skipping meals, and cutting of food.

\section{Inappropriate cutting-out of food}

Among food groups considered for cutting out, starchy food (e.g., rice) was the most common with at least two to ten participants practicing this behavior. On the other hand, almost the same proportion of participants was engaged in cutting out of dairy and meat products/food in their diet at 5.6 percent and 5.9 percent, respectively. Since consumption of rice is staple in the Philippine context, higher proportion ( $22 \%$ among males and females) of the respondents cut-out this type of food on their diet compared to meat or dairy.

Table 7 shows the number and proportion of participants cutting-out at least one food group inappropriately by type of weight misperception. Results showed that prevalence of practicing inappropriate cutting-out of food was higher among those who over-estimated their BMI status at 34.8 percent compared to 23.3 percent of those who did not. The same trend is also evident among those participants who correctly identified their BMI status.

Table 7. Weight Misperception by Inappropriate Cutting-out of Food, Undergraduate Students of UPM $2^{\text {nd }}$ Semester AY 2016-2017

\begin{tabular}{|c|c|c|c|c|c|c|c|c|}
\hline \multirow{3}{*}{ Weight Misperception } & \multicolumn{8}{|c|}{ Inappropriate cutting-out of food } \\
\hline & \multicolumn{2}{|c|}{ No } & \multicolumn{2}{|c|}{ Yes } & \multicolumn{2}{|c|}{ Missing } & \multicolumn{2}{|c|}{ Total } \\
\hline & No & $\%$ & No & $\%$ & No & $\%$ & No & $\%$ \\
\hline Same Estimate & 251 & 54.2 & 82 & 51.9 & 0 & 0 & 333 & 53.3 \\
\hline Overestimate & 108 & 23.3 & 55 & 34.8 & 0 & 0 & 163 & 26.1 \\
\hline Underestimate & 91 & 19.7 & 17 & 10.8 & 0 & 0 & 108 & 17.3 \\
\hline Missing & 13 & 2.8 & 4 & 2.5 & 4 & 100 & 21 & 3.4 \\
\hline
\end{tabular}


Socio-demographic factors could influence the association of weight misperception and practice of inappropriate cutting-out of food. Table 8 presents the crude odds ratio measuring the association of each possible confounder with weight misperception. Those who had lower financial capacity to pay their tuition (Bracket B and grouped Bracket $\mathrm{C}, \mathrm{D}$ and $\mathrm{E}$ ) as described by the STS bracketing were less likely to engage in inappropriate cutting-out of food compared to those in the highest bracket (Bracket A). They were 39 percent and 26 percent less likely, respectively, to engage in cutting out of food inappropriately. Physical activity also seemed to be a risk factor for practicing inappropriate cutting-out of food. The association was significant $(\mathrm{p}=0.012)$ among participants that engaged in more than 2 days of physical activity.

Among these socio-demographic characteristics, only STS bracket and physical activity were probable confounders. However, the change in estimate method proposed by Hosmer and Lemeshow ${ }^{18}$ also showed no significant confounders in the model. Table 9 showed the final model. Based on this, the odds of practicing inappropriate cuttingout of food among those who overestimated their BMI status was significantly higher by 1.56 times $(p=0.034)$ than the odds of practicing the said behavior among those who accurately identified their BMI status.

Results from the study in terms of confounders add to the growing differences in the literature concerning factors associated with unhealthy diet-related behavior. In this study, though socio-economic status, physical activity, and college group were identified to be probable confounders, none were significant.

\section{CONCLUSION AND RECOMMENDATIONS}

Based on this study among the undergraduate students of U.P. Manila, it was seen that $53.28 \%$ of the students accurately perceived their BMI status, $26.08 \%$ overestimated their BMI status, while $17.28 \%$ underestimated their BMI status. It was also seen that over-estimating of BMI status was more associated with unhealthy dietary practices. Overestimators of BMI were 1.95 times more likely to skip meals $(p=0.001)$ and 1.56 times more likely to engage in inappropriate cutting of food $(\mathrm{p}=0.034)$.

Among U.P. Manila undergraduate students, sex (male or female) and age were not associated with the highlighted unhealthy dietary practices by the study. This is in contrast with previous studies that showed that age and sex as significant factors in predicting likelihood of engaging in unhealthy diet practices. Those that engaged in more than 2 days of physical activity on the other hand had significant association with skipping meals and inappropriate cutting of food. This might be based on the idea that active people are more likely conscious of their weight and are more likely to engage in activities related to weight loss. Socioeconomic status modelled by the proxy variable STS bracket
Table 8. Odds ratio and p-value of probable confounders and inappropriate cutting-out of food, Undergraduate Students of UPM $2^{\text {nd }}$ Semester AY 2016-2017

\begin{tabular}{lll}
\multicolumn{1}{c}{ Variable } & OR & p-value \\
$\begin{array}{l}\text { Age group } \\
18-19\end{array}$ & Base & \\
20 and above & 0.99 & 0.973 \\
\hline Sex & & \\
$\quad$ Male & Base & \\
Female & 1.21 & 0.336 \\
\hline STS & & \\
A & Base & \\
B & 0.61 & 0.036 \\
C, D, E and others & 0.74 & 0.161 \\
\hline Degree & & \\
Bachelor of Science & Base & \\
Bachelor of Arts & 1.13 & 0.580 \\
\hline UPM colleges & & \\
Arts and Sciences & Base & \\
Allied Medical Professions & 0.65 & 0.205 \\
Dentistry & 1.46 & 0.244 \\
Nursing & 0.94 & 0.874 \\
Pharmacy & 0.62 & 0.087 \\
Public Health & 1.27 & 0.399 \\
\hline Physical Activity & & \\
None & Base & \\
1-2 days & 1.39 & 0.147 \\
more than 2 days & 1.82 & 0.012 \\
\hline
\end{tabular}

Table 9. Reduced model of the Association of Weight Misperception and Inappropriate cutting-out of food, Undergraduate Students of UPM $2^{\text {nd }}$ Semester AY 2016-2017

\begin{tabular}{cccccc} 
Variable & $\begin{array}{c}\text { Odds } \\
\text { ratio }\end{array}$ & $\begin{array}{c}\text { Std } \\
\text { Error }\end{array}$ & p-value & $\mathbf{9 5 \%} \mathbf{C l}$ \\
\hline $\begin{array}{c}\text { Weight Misperception } \\
\text { Same estimate }\end{array}$ & Base & & & & \\
Over estimate & 1.56 & 0.33 & 0.034 & 1.04 & 2.35 \\
Under estimate & 0.57 & 0.17 & 0.057 & 0.32 & 1.02 \\
Constant & 0.33 & 0.04 & 0.000 & 0.25 & 0.42 \\
\hline
\end{tabular}

was seen to have a significant association with those that engaged in inappropriate cutting of food. Students from Bracket B were $39 \%$ less likely to cut food than Bracket A.

It is recommended to adopt a longitudinal design to determine whether students change their weight misperception as they continue with their undergraduate degree program. It might also be worth extending the investigation to a different university to increase the generalizability of the results of a future study. The study also focused on unhealthy practices related to weight loss. This resulted in statistically significant association among over estimators of their BMI status. One may look at practices related to weight gain which could probably give more insight among under-estimators of BMI status. 


\section{Statement of authorship}

All authors approved the final version submitted.

\section{Authors disclosure}

All authors declared no conflict of interest.

\section{Funding source}

This paper was self-funded and was implemented as part of Biostatistics 206.1 course in UPM College of Public Health.

\section{REFERENCES}

1. Almenara CA, Fauquet J, López-Guimerà G, Pamias Massana M, Sánchez-Carracedo D. Self-perceived weight status, dieting and unhealthy weight-control behaviors among Spanish male adolescents. Nutr Hosp. 2014; 30(2):301-5.

2. World Health Organization. Obesity and Overweight - Fact Sheet [Internet]. 2015 [cited $2016 \mathrm{Feb}$ ]. Available from http://www.who. int/mediacentre/factsheets/fs311/en/

3. Nazeri A, Massumi A, Wilson JM, Frank CM, Bensler M, Cheng J, et al. Arrhythmogenicity of weight-loss supplements marketed on the Internet. Heart Rhythm. 2009; 6(5):658-62.

4. Blanck HM, Serdula MK, Gillespie C, Galuska DA, Sharpe PA, Conway JM, et al. Use of nonprescription dietary supplements for weight loss is common among Americans. J Am Diet Assoc. 2007; 107(3):441-7.

5. Euromonitor. Meal Replacement Trends[Internet]. Euromonitor International. 2016 [cited 2018 Mar]. Available from https:// blog.euromonitor.com/2016/01/meal-replacement-trends-thetransformation-from-a-weight-management-solution-to-awellbeing-inspiration.html

6. Bishop R. More than meets the eye: an exploration of literature related to the mass media's role in encouraging changes in body image. Annals of the International Communication Association. 2000; 23(1):271-304.

7. Talamayan KS, Springer AE, Kelder SH, Gorospe EC, Joye KA. Prevalence of overweight misperception and weight control behaviors among normal weight adolescents in the United States. Scientific World Journal. 2006; 6:365-73.
8. Saleem MD, Ahmed G, Mulla J, Haider SS, Abbas M. Weight misperception amongst youth of a developing country: Pakistan a cross-sectional study. BMC Pubic Health. 2013; 13:707.

9. Jiang Y, Kempner M, Loucks E. Weight misperception and health risk behaviors in youth: The 2011 US YRBS. Am J Health Behav. 2014; 38(5):765-80.

10. Ibrahim C, El-Kamary S, Bailey J, St George DM. Inaccurate weight perception is associated with extreme weight management practices in US high-school students. J Pediatr Gastroenterol Nutr. 2014. 58(3):368-75.

11. Grigg M, Bowman J, Redman S. Disordered Eating and Unhealthy Weight Reduction Practices among Adolescent Females. Prev Med. 1996; 25:748-56.

12. Hadland SE, Austin SB, Goodenow CS, Calzo JP. Weight misperception and unhealthy weight control behaviors among sexual minorities in the general adolescent population. J Adolesc Health. 2014; 54(3):296-303.

13. Weng C. Unhealthy weight control behaviors among high school students. Dissertation [Internet]. University of Florida. 2011 [cited 2017 Mar]. Available from http://ufdcimages.uflib.ufl.edu/ UF/E0/04/36/77/00001/WENG_C.pdf

14. Florentino RF. State of the Art of Obesity Research in the Philippines: 1981 - 2011. Review, Philippine Association for the Study of Overweight and Obesity. 2012.

15. Center for Disease Control. Metric BMI Calculator [Internet]. 2015. [cited $2018 \mathrm{Mar}$. Available from https://www.google.com. $\mathrm{ph} / \mathrm{search}$ ? safe=active\&rlz=1C1LENN_enPH467PH467\&btnG= Search\&q=CDC+BMI+calculator+excel+metric\#

16. University of the Philippines. Socialized Tuition System [Internet]. 2014 [cited 2018 Mar]. Available from https://www.up.edu.ph/ index.php/admissions/socialized-tuition-system/

17. Centers for Disease Control and Prevention, U.S. Department of Health and Human Services. Center for Surveillance, Epidemiology, and Laboratory Services [Internet].Youth Risk Behavior Surveillance - United States. 2013 [cited 2018 Mar]. Available from https:// www.cdc.gov/mmwr/preview/mmwrhtml/ss6304a1.htm

18. Lemeshow S, Hosmer Jr DW. Estimating odds ratios with categorically scaled covariates in multiple logistic regression analysis. Am J Epidemiol. 1984; 119(2):147-51. 